\title{
$\therefore$ \\ Facial Nerve Paralysis and its Social and Psychological Impact - A Review
}

IJCRR

Section: Healthcare

ISI Impact Factor

(2019-20): 1.628

IC Value (2019): 90.81

$\operatorname{SJIF}(2020)=7.893$

(c) (i) (3)

Copyright@IJCRR

\section{Swain SK ${ }^{1}$, Panda $\mathbf{S}^{1}$, Das $\mathbf{S}^{\mathbf{2}}$}

\author{
'Department of Otorhinolaryngology, IMS and SUM hospital, Siksha "O” Anusandhan University, K8, Kalinganagar, Bhubane- \\ swar-751003, Odisha, lndia; 'Central Research Laboratory, IMS and SUM hospital, Siksha "O" Anusandhan University, K8, Kalinganagar, \\ Bhubaneswar-751003, Odisha, India.
}

\section{ABSTRACT}

Facial nerve paralysis is a common clinical entity found in routine practice. A facial palsy is a form of facial disfigurement and the patient usually experience severe psychological and social manifestations. Although facial palsy is not a life-threatening disease, it is associated with higher rates of morbidity along with social stigma if stays for a longer period. Although there are several studies for etiologies, clinical presentations and management for facial nerve paralysis palsy, but the majority do not provide any insight into the social impact of facial palsy. Facial palsy has several ranges of effects on the quality of life. It can affect in a variety of ways such as difficulty in facial expression, speech, vision, drinking and eating. It can also result in physical discomfort and psychosocial manifestations. Functional and aesthetic deficits in facial nerve paralysis impair the quality of life in affected patients. Management of the social stigma related to facial palsy is more challenging and can be resolved with medications, surgery, facial exercises and proper counselling with patients and their family members. This review article provides an overview of the social and psychological impact of facial nerve paralysis.

Key Words: Facial nerve paralysis, Social impact, Psychological impact, Bell's palsy, Depression, Quality of life

\section{INTRODUCTION}

Facial nerve paralysis is a common cranial neuropathy resulting in loss of symmetry of the face. Paralysis of the facial nerve often affects the facial appearance and cause paralysis of any structures innervated by the facial nerve. In the perspective of peripheral facial nerve paralysis, there are psychological and social issues are found in patients with facial palsy. The human face is a vital part of the body that serves an important role in social interaction, emotion, sexual dimorphism and overall health. ${ }^{1}$ Face is a vital body part for self-concept and psychologically the most important part of the human body. ${ }^{2}$ The face of the human body is an essential component in the person's psychic and social functioning as its expression mediates the social interaction and affect the constitution of subjectivity. What makes a "normal" facial look has been shaped by society and any change or deviation from this normal one can result in stigmatization. The paralysis of the facial nerve can occur from idiopathic, congenital, neoplastic, iatrogenic, infections and other inflammatory causes. ${ }^{3}$ Bell's palsy is the commonly encountered facial nerve palsy in routine clinical practise where the patient pre- sents with acute unilateral lower motor neuron facial nerve paralysis. ${ }^{4}$ Ischemic, immune and infective mechanisms are all the potential contributors for the development of Bell's palsy but the exact cause remains unclear. ${ }^{5}$ In facial nerve palsy, impaired movement of the face and reduced facial expression can pose challenges in the face to face communications. ${ }^{6}$ The functional deficits in facial nerve paralysis or Bell's palsy include difficulties in eating, drinking, speaking, intimate human information and emotional expression. ${ }^{7}$ These functional deficits are usually associated with the psychological aspect of the human being which can result in social and psychological difficulties for the patients with facial palsy including decreased self-esteem, anxiety, depression and social isolation. ${ }^{8}$ The sudden onset of facial nerve palsy with unknown cause as in Bell's palsy will contribute to more psychological distress among patients. As facial palsy is rarely significant in the daily life of a person, the experience related to the social and psychological aspects is less studied. Here, this review article summarizes the epidemiology, etiopathology, social impact and psychological impact of the facial nerve paralysis of the patients concerning the functional and cosmetic deterioration.

\section{Corresponding Author:}

Swain SK, Professor, Department of Otorhinolaryngology, IMS and SUM hospital, Siksha “O” Anusandhan University, K8, Kalinganagar, Bhubaneswar-751003, Odisha, India; Cell: +91-9556524887; Email: santoshswain@soa.ac.in

ISSN: 2231-2196 (Print)

Received: 22.01 .2021
ISSN: 0975-5241 (Online)

$$
\text { Revised: } 20.02 .2021
$$

Published: 26.05 .2021 


\section{METHODS OF LITERATURE SEARCH}

For searching the published research articles, we conducted an electronic survey of the Scopus, Medline, Google Scholar and PubMed database. The search terms in the database included facial nerve paralysis, Bell's palsy, social impact, the psychological impact of the facial nerve paralysis. The abstracts of the published articles were identified by this search method and other articles were identified manually from citations. This manuscript reviews the etiopathology, epidemiology, social impact, psychological impact and treatment of facial nerve paralysis. This review article presents a baseline from where further prospective trials for the social and psychological impact of facial nerve paralysis could be designed and helps as a spur for further research in this psychosocial aspect of facial nerve paralysis.

\section{EPIDEMIOLOGY}

Facial nerve palsy is a common cranial mono-neuropathy. Facial nerve palsy often affects males and females equally and has a little higher incidence in the mid and later part of life but is certainly found across all the age ranges. The social and psychological stigma is more associated with female patients with facial nerve paralysis. ${ }^{9}$ The incidence of Bell's palsy ranges from 11.5 to 40.2 per 100,000 populations. ${ }^{10}$ The annual incidences of Bell's palsy in the UK is $20.2 / 100,000$ and in Japan is $30 / 100,000$ and in the USA is 25 to $30 / 100,000 .{ }^{10}$ The incidence of facial nerve paralysis specifically Bell's palsy us higher during pregnancy, following viral upper respiratory tract infection in immunocompromised patients and patients with diabetes mellitus and hypertension. ${ }^{11}$ Some epidemiological data showed seasonal variations of the facial nerve paralysis with a slightly higher incidence in winter or cold months versus summer or warm months and slightly preponderance to arid over non-arid climates. ${ }^{10}$

\section{ETIOPATHOLOGY OF THE FACIAL NERVE PARALYSIS}

The facial nerve is the seventh cranial nerve (CNVII) and consists of motor, sensory and parasympathetic components. The facial nerve gets axons from the superior part of the solitary nucleus and superior salivary nucleus which form nervus intermedius component (sensory and parasympathetic axons) and motor efferent fibres from the facial nucleus, which receives the synaptic input from the opposite side motor cortex for all the facial movements except the forehead which has bi-cortical input. ${ }^{12}$ The facial nerve is the most commonly affected nerve of the human body as it passes through a 35 $\mathrm{mm}$ bony canal and is so subject to the compression and in- fectious processes of different etiologies which may block the nervous influx, causing the complete blockage of its function. ${ }^{13}$ Ischemic, immune and infective mechanisms are considered as potential contributors for the development of Bell's palsy but the exact cause remains unclear. ${ }^{14}$ The aetiology for facial nerve paralysis include inflammatory causes, tumours, metabolic disorders, herpes zoster and idiopathic or Bell's palsy. ${ }^{12}$ Bell's palsy constitutes two-thirds of the cases of peripheral facial nerve paralysis. ${ }^{15}$

The toddlers (children between ages 1 to 3 years) and preteenagers (between age 8 and 12 years) may be at higher risk for development of the facial nerve paralysis due to infectious and traumatic aetiology. ${ }^{15}$ One study on the congenital cause of facial nerve paralysis, the majority of the facial nerve paralysis is associated with forceps delivery. The function of the facial nerve is for voluntary and mimetic facial movement, taste sensation to the anterior third of the tongue and controlling the secretions of the submandibular and sublingual salivary glands and lacrimal secretions. ${ }^{16}$ So, the paralysis of the facial nerve results in functional and cosmetic aspects of the person. The clinical manifestations depend on the amount of neural injury. ${ }^{17}$ The peripheral facial nerve paralysis results in psychic and social impacts, which drastically disturb the facial expression and limit the possibility of evidence of their emotional feelings. Therefore, it may create communication disorders. ${ }^{18}$ The sequelae of the facial nerve paralysis may be seen when associated with partial neural regeneration, causing post-paralytic hemifacial spasm and/ or persistent motor deficit with contracture of the facial muscles. Synkinesis is also sequelae and results in discomfort which distort movements of the face and facial expression in addition to compromising the facial symmetry during rest. Other sequelae of the facial nerve paralysis are permanent hypofunction of the affected muscles of the face, typical of the flaccid phase of the peripheral facial nerve paralysis. ${ }^{19}$

\section{SOCIAL IMPACT OF THE FACIAL NERVE PARALYSIS}

The face of the human body is an essential component responsible for a person's psychic and social functioning as the facial expression mediate social interaction and highly affect the constitution of subjectivity. ${ }^{20}$ The facial nerve paralysis drastically slows the facial expression, so this condition impairs the communication of the patient to fellow persons. ${ }^{21}$ The patients with facial disfigurements are usually stigmatized by society because of the appearance different from "normal" and valued inferior to others who are not associated with facial deviation or disfigurement. ${ }^{22}$ The patients of the facial nerve paralysis usually present with sudden onset, lower motor neuron type facial nerve paralysis with accompanying symptoms such as dysgeusia, postauricular pain and 
hyperacusis. There are different scales are used for quantifying facial nerve impairment or paralysis. House Brackmann grading system is utilized routinely by clinicians to evaluate the grading of the facial nerve functions in facial nerve paralysis. ${ }^{6}$ The House Brackmann grading for the facial nerve palsy includes Grade 1-Normal; Grade:2-Mild dysfunction; Grade:3-Moderate dysfunction; Grade:4-Moderately dysfunction; Grade:5-Severe dysfunction; Grade:6-Total paralysis. ${ }^{23}$ Although it has an important role in the clinical evaluation of facial palsy, cannot capture the patient's perception of the psychological and social aspect of the facial nerve paralysis which are important components of their facial image. If we will consider social interaction, the face accounts for an essential element in any society. Routine social interaction involves face to face discussion where the face plays an important role or emotions and produce mutual recognization. ${ }^{24}$ The paralysis of the seventh cranial nerve is usually immediately obvious in Bell's palsy. Persons with Bell's palsy have visibly shown differences in facial appearance, regardless of when they acquired facial nerve paralysis and deal with a lot of social stigma and discrimination. In the case of Bell's palsy, the patient often experiences shock due to social stigma which contributes to challenges faced by society because of the alteration of the facial appearance. It results in weakness of the muscles of the face, impacting the verbal communication, social interaction in respect to the facial expression, oral competence, taste, protection of the cornea, protection of the ocular globe and vision of the patient with Bell's palsy. Functional problems like eating and drinking in patients with facial palsy can cause embarrassment. The functional problems of facial palsy may extend to the eye, causing a functionally dry eye with the inability to blink and it leads to corneal damage. ${ }^{25}$ In facial palsy, the inability to smile and express emotions cause the most distress to the patients. ${ }^{26}$ Bell's palsy is a devastating clinical condition causing functional and aesthetic deficits. ${ }^{27}$ The synkinesis is often found in the face of the patient with facial nerve paralysis. Synkinesis refers to the abnormal muscular contraction in the face during voluntary facial movements and it is due to aberrant re-innervations of the facial musculature after nerve injury. It can be found as involuntary eye closure at the time of mid-face movement such as smiling or eating(oro-ocular synkinesis); lip excursion during eye closure(oculo-oral synkinesis) or chin dimpling or muscular neck cords during mid-face movement because of the involuntary mentalis or platysma activation. ${ }^{28}$

\section{PSYCHOLOGICAL IMPACT OF THE FACIAL NERVE PARALYSIS}

The emotions of the human being are usually communicated through facial expressions. Happiness, sorrow, confusion and frustration can be expressed by a slight smile, eyebrow shift or even by a wrinkled nose. Facial nerve paralysis can result in the inability of performing volitional mimetic movement which can provoke anxiety. ${ }^{29}$ Female patients had significantly higher levels of anxiety in comparison to male patients. ${ }^{29}$ The depression was also more in male patients than females. ${ }^{29}$ Persons with facial paralysis are more likely to suffer from depression and anxiety than the general population, particularly if the paralysis occurs later in life rather than at birth. ${ }^{30}$ Persons who acquire paralysis in the late part of life feel a real sense of loss or alteration on identification than those born with facial paralysis doesn't experience. Persons with facial nerve paralysis often report being turned down for public-facing jobs or leadership roles. They are also perceived as unfriendly or uninterested because of their appearance of face after facial nerve paralysis. The deficits due to facial muscle paralysis such as lagophthalmos and impaired oral function lead to psychological distress and impaired interpersonal communication. ${ }^{31}$ In facial nerve paralysis, there is facial disfigurement and the patient usually experience severe psychological and social manifestations. In this case, the facial expression is altered or diminished which affect the normal face to face communication with other persons and even the non-verbal facial expression may be misinterpreted. Functional problems such as eating and drinking often result in embarrassment. ${ }^{32}$ In Bell's palsy, the symptoms are usually sudden in onset which enhances the psychological distress of the affected patients. ${ }^{33}$ There are high chances of depression and decreased social contacts documented in the patients of facial palsy. ${ }^{34}$ The psychological distress rather than the functional deficits by facial nerve paralysis is the most important predictor of the social disability in Bell's palsy. ${ }^{35}$ In facial nerve paralysis, the selfperception of the facial look, psychological well-being, social functioning, physical functioning and overall well-being is an important component in the patients with Bell's palsy.

\section{PEDIATRIC PATIENTS WITH FACIAL NERVE PARALYSIS}

There are several implications associated with facial nerve paralysis of the pediatric patients as seen in a 5-year-old child with left side Bell's palsy (Fig.1). It results in serious clinical manifestations as it leads to significant concerns in the clinicians because of its aetiology, treatment options and outcome in pediatric patients and also among parents, because of its functional and aesthetic results. The aetiology of facial nerve paralysis in pediatric patients may be congenital (labour trauma, genetic or malformative diseases) or acquired(infective, inflammatory, neoplastic, traumatic or iatrogenic). ${ }^{36}$ Infants A careful clinical evaluation and diagnosis are suggested in the case of pediatric facial nerve paralysis to provide effective treatment and psychological support to the children and their parents. 
Facial nerve paralysis in pediatric patients may result in devastating situations and the parents present with not unreasonable concerns towards the well-being of their children. When pediatric patients are affected with facial nerve paralysis, it has a tremendous impact on the patients as well as family members. The child with facial paralysis may feel hesitant to out in public, participate to play with other children and even shy away from interacting with friends and families. Facial palsy may cause alteration speech, chewing, tasting, swallowing, salivation and lacrimation in children. It also manifests in hyperacusis and hypoesthesia in the external auditory canal. ${ }^{37}$ Asthetically, the disharmony between the facial movements and speech results in embarrassment, not only for the patients with facial palsy but also for those around them. Therefore, this condition results in functional and aesthetical problems for the children and their families.

\section{TREATMENT}

The goal for treatment of facial nerve paralysis include eye protection, give symmetry of the face at rest, restoring to the normal facial movement and getting independent, voluntary and spontaneous facial expressions. The clinicians are usually alert for improvement of the recovery of facial nerve function, prevention of neural degeneration and its complications. The treatment of facial nerve paralysis is related to the exact aetiology and the severity of the paralysis itself. The treatment of patients with facial nerve paralysis is ideally done in a multidisciplinary approach with otolaryngologists, facial-plastic surgeons, ophthalmologists, physiotherapists, speech therapists and specialized trained chemo-denervation nurses. ${ }^{38} \mathrm{~A}$ psychologist specialized in psychosocial consequences of facial nerve paralysis is also an important part of the multidisciplinary team. Psychological counselling is a must in all patients with facial nerve paralysis to ameliorate the potential psychosocial dysfunction in patients with facial nerve paralysis. The medical treatment of the commonly encountered facial palsy includes steroids and antiviral drugs. ${ }^{38}$ The glucocorticoids in tapering dose and antivirals (acyclovir or valacyclovir) are recommended in the case of Bell's palsy and the majority of the patients improve in the first three weeks. However, intravenous steroids along with antivirals are often prescribed for Ramsay Hunt syndrome. In the case of persistent facial palsy, different techniques utilized for the treatment of Bell's palsy include nerve grafting and transfer, botulinum toxin injection, static slings, brow lifts, gold weights, regional muscle transfer and free functional muscle transfers. ${ }^{39}$ As there are large numbers of treatment options available, each treatment option is unique and individualized. There should be greater protection against discrimination and bullying towards persons with facial nerve paralysis in society. Stigma is the important predictor for the origin of anxiety and depression, so this is a socially created problem and can be acted upon. In the present scenario, specialized support groups are needed for helping patients with facial palsy experiencing psychological distress. They should provide therapies including facial palsy rehabilitation and communication skill training. The recovery of the facial nerve paralysis often takes one month or less in cases of infectious aetiology whereas 8 months in cases of traumatic causes. ${ }^{15}$ In case of traumatic aetiology. The recovery is always substantial to complete except in cases of reconstruction and lacerations. In case of incomplete recovery of the facial nerve palsy with an ineffective smile, nerve to nerve transfer and regional and free tissue transfer methods provide the opportunity to restore the mid-face movement. The innervated free muscle transfer such as gracilis muscle can also be utilized and inserted into the face with nerve coaptation from the contralateral facial nerve and/or same side mandibular branch of the trigeminal nerve. Currently, nerve to nerve transfer is utilized for those with auto preservation of the facial muscles but a frozen oral commissure. The donor's nerves are the masseter branch of the trigeminal nerve and cross face nerve grafting. These complex surgical procedures provide an opportunity for smile reanimation and further benefits in social and quality of life. ${ }^{40}$

\section{CONCLUSION}

Facial nerve paralysis has a tremendous impact on the patient as well as on his or her family. Family and social support are known to play an important role in the psychological well-being of the patient with facial nerve paralysis palsy. Patients with facial palsy often suffer from significant psychosocial issues. The result of facial paralysis results in a negative impact on social perception. Patients with disability by facial nerve palsy show greater psychological distress and the more psychological distress present a poorer quality of life. Treatment of the functional problems associated with facial nerve palsy alone is not enough. The functional problem might be resolved with adequate treatment but the social and psychological impact of it may remain. This review article will surely help the clinicians to understand the situations of the patients and manage them accordingly.

\section{Acknowledgement: None}

\section{Conflict of interest: Nil}

Funding: No funding sources were granted or used specifically for this work.

Author Contribution: Prof.Santosh Kumar Swain: Concept, data collection and data analysis; Dr.Swaha Panda: 
Data collection and drafting; Mr.Somadatta Das: Data collection.

\section{REFERENCES}

1. Frith C. Role of facial expressions in social interactions. Philos Trans R Soc Lond Ser B Biol Sci. 2009; 364(1535):3453-3458.

2. Slade PD, Russell GF. Experimental investigations of bodily perception in anorexia nervosa and obesity. Psychother Psychosom. 1973; 22(2-6): 359-363.

3. Kahn JB, Gliklich RE, Boyev KP, Stewart MG, Metson RB, McKenna MJ. Validation of a patient-graded instrument for facial nerve paralysis: The FaCE scale. Laryngosc. 2001; 111(3):387398.

4. Swain SK, Behera IC, Sahu MC. Bell's palsy among infants-Our experiences in a tertiary care hospital of eastern India. Asian J Pharm Clin Res. 2017;10(9):85-87.

5. Peitersen E. Bell's palsy: the spontaneous course of 2,500 peripheral facial nerve palsies of different etiologies. Acta Otolaryngol Suppl. 2002; 122(7):4-30.

6. Bradbury ET, Simons W, Sanders R. Psychological and social factors in reconstructive surgery for hemifacial palsy. J Plast Reconstr Aesthet Surg. 2006; 59(3):272-278.

7. Ekman P. Psychosocial aspects of facial paralysis. In: May M, ed. The Facial Nerve. New York: Thieme Med; 1986:781-787.

8. Ross B, Nedzelski JM, McLean JA. Efficacy of feedback training in long-standing facial nerve paresis. Laryngoscope. 1991; 101(7):744-750.

9. Swain SK, Pattnaik T, Mohanty JN. Otological and rhinological manifestations in pregnancy: Our experiences at a tertiary care teaching hospital of East India. Int J of Health \& Allied Sci. 2020;9(2):159-63.

10. Myeres EN,De Diego JI, Prim MP, Madero R, Gavil \$ Aan JA. Seasonal patterns of idiopathic facial paralysis: a 16-year study. Otolaryngol Head Neck Surg. 1999;120:269-71.

11. Peitersen E. Bell's palsy: the spontaneous course of 2,500 peripheral facial nerve palsies of different etiologies. Acta Otolaryngol Suppl. 2002;122(7):4-30.

12. Swain SK, Sahu MC, Behera IC. Management of Ramsay Hunt syndrome among HIV patients: Our experience in a tertiary care hospital of eastern India.Pol Ann of Med. 2016;23(2)-92-96.

13. Hudson TJ, Gare B, Allen DG, Ladak HM, Agrawal SK. Intrinsic measures and shape analysis of the intratemporal facial nerve. Otol \& Neurotol.2020;41(3):378-786.

14. Swain SK, Behera IC, Sahu MC. Head injury with sudden onset bilateral facial palsy-Can happens without temporal bone fractures and brain injury!. J of Ear, Nose, Throat and Allied Sci. 2016;17(1):23-25.

15. Evans AK, Licameli G, Brietzke S, Whittemore K, Kenna M. Pediatric facial nerve paralysis: Patients, management and outcomes. Int J of Ped Otorhinolaryngol. 2005; 69(11): 1521-1528.

16. Swain SK, Das A, Munjal S.A rare cause of bilateral facial nerve paralysis due to acute otitis media in a 52-year-old man. Med J of Dr.DY Patil Vidyapeeth. 2020;13(6):688-691.

17. Batista KT. Paralisia facial: análise epidemiológica em hospital de reabilitação. Rev Bras Cir Plast. 2011;26(4):591-495.

18. Silva MFF, Cunha MC, Lazarini PR, Fouquet ML. Conteúdos psíquicos e efeitos sociais associados à paralisia facial periférica: abordagem fonoaudiológica. Arq Int Otorrinolaringol. 2011;15(4):450-460.

19. Freitas KCS, Goffi-Gomez MV. Grau de percepção e incômodo quanto à condição facial em indivíduos com paralisia facial periférica na fase de sequelas. Rev Soc Bras Fonoaudiol.
2008;13(2):113-118.

20. Camargos CN, Mendonça CA, Duarte SM. Da imagem visual do rosto humano: simetria, textura e padrão. Saúde Soc. São Paulo 2009;18(3):395-410.

21. Ho AL, Scott AM, Klassen AF, Cano SJ, Pusic AL, Van Laeken $\mathrm{N}$. Measuring quality of life and patient satisfaction in facial paralysis patients: a systematic review of patient-reported outcome measures. Plast Reconstr Surg. 2012;130(1):91-99.

22. Urban E, Volk GF, Geibler K, Thielker J, Dittberner A, Klinger C, et al. Prognostic factors for the outcome of Bell's palsy: A Cohort register-based study. Clin Otolaryngol. 2020;45(5):754761.

23. Samsudin WS, Samad R, Sundaraj K, Mustafa M, Abdullah NR. Correlation of objective assessment of facial paralysis with House-Brackmann score. Telkomnika. 2017;15(2):829-835.

24. Díaz-Aristizabal U, Valdés-Vilches M, Fernández-Ferreras TR, Calero-Mũnoz E, Bienzobas-Allué E, Moracén-Naranjo T. Correlations between impairment, psychological distress, disability, and quality of life in peripheral facial palsy. Neurología. 2019;34(7):423-428.

25. Rahman I, Sadiq SA. Ophthalmic management of facial nerve palsy: a review. Surv Ophthalmol. 2007; 52(2):121-144.

26. Bradbury ET, Simons W, Sanders R. Psychological and social factors in reconstructive surgery for hemifacial palsy. J Plastic Reconstr Aesth Surg. 2006; 59(3): 272-278.

27. Rosson GD, Redett RJ. Facial palsy: anatomy, aetiology, grading, and surgical treatment. J Reconstr Microsurg. 2008; 24 (6):379-389.

28. Hadlock TA, Greenfield LJ, Wernick-Robinson M, Cheney ML. Multimodality approach to the management of the paralyzed face. Laryngosc. 2006;116(8):1385-1389.

29. Hotton M, Huggins E, Hamlet C, Shore D, Johnson D, Norris $\mathrm{JH}$, et al. The psychosocial impact of facial palsy: A systematic review. Br J of Health Psych. 2020;25(3):695-727.

30. Bogart KR. Socioemotional functioning with facial paralysis: Is there a congenital or acquired advantage? Health Psych. 2019; 39(4):345-354.

31. Ho AL, Scott AM, Klassen AF, Cano SJ, Pusic AL, Van Laeken N. Measuring quality of life and patient satisfaction in facial paralysis patients: a systematic review of patient-reported outcome measures. Plast Reconstr Surg.2012; 130 (1): 91-99.

32. Weir A, Pentland B, Crosswhite A, Murray J, Mountain R. Bell's palsy: the effect on self-image, mood state, and social activity. Clin Rehabil. 1995; 9(2): 121-125.

33. Coulson SE, O'Dwyer NJ, Adams RD, Croxson GR. Expression of emotion and quality of life after facial nerve paralysis. Otol Neurotol. 2004; 25 (6): 1014-1019.

34. Bajaj-Luthra A, VanSwearingen J, Thornton R, Johnson P. Quantitation of patterns of facial movement in patients with ocular to oral synkinesis. Plast Reconstr Surg.1998; 101 (6): 1473-1480.

35. VanSwearingen JM, Cohn JF, Turnbull J, Mrzai T, Johnson P. Psychological distress: Linking impairment with disability in facial neuromotor disorders. Otolaryngol Head Neck Surg.1998; 118(6):790-796.

36. Pourmomeny AA, Asadi S.Management of Synkinesis and asymmetry in facial nerve palsy:a review article.Iran J Otolaryngol. 2014;26(77):251-256.

37. Vasconcelos BEC, Dias E, Dantas WRM, Barros ES, Monteiro GQ. M. Paralisia facial periférica traumática. Rev Cir Traumat Buço-Maxilo-Facial. 2001;1(2):13-20.

38. Swain SK,Behera IC,Sahu MC.Head injury with sudden onset bilateral facial palsy-Can happen without temporal bone fractures and brain injury!. Egypt J of Ear,Nose,Throat and Allied Sci. 2016;17(1):23-25. 
39. Swain SK, Das A, Mohanty JN. Acute otitis media with facial nerve palsy: our experiences at a tertiary care teaching hospital of eastern India. J of Acute Dis. 2019;8(5): 204-207.
40. Labbé D, Bénateau H, Bardot J. Surgical procedures for labial reanimation in facial paralysis. Ann Chir Plast Esthet. 2002;47(5):580-591.

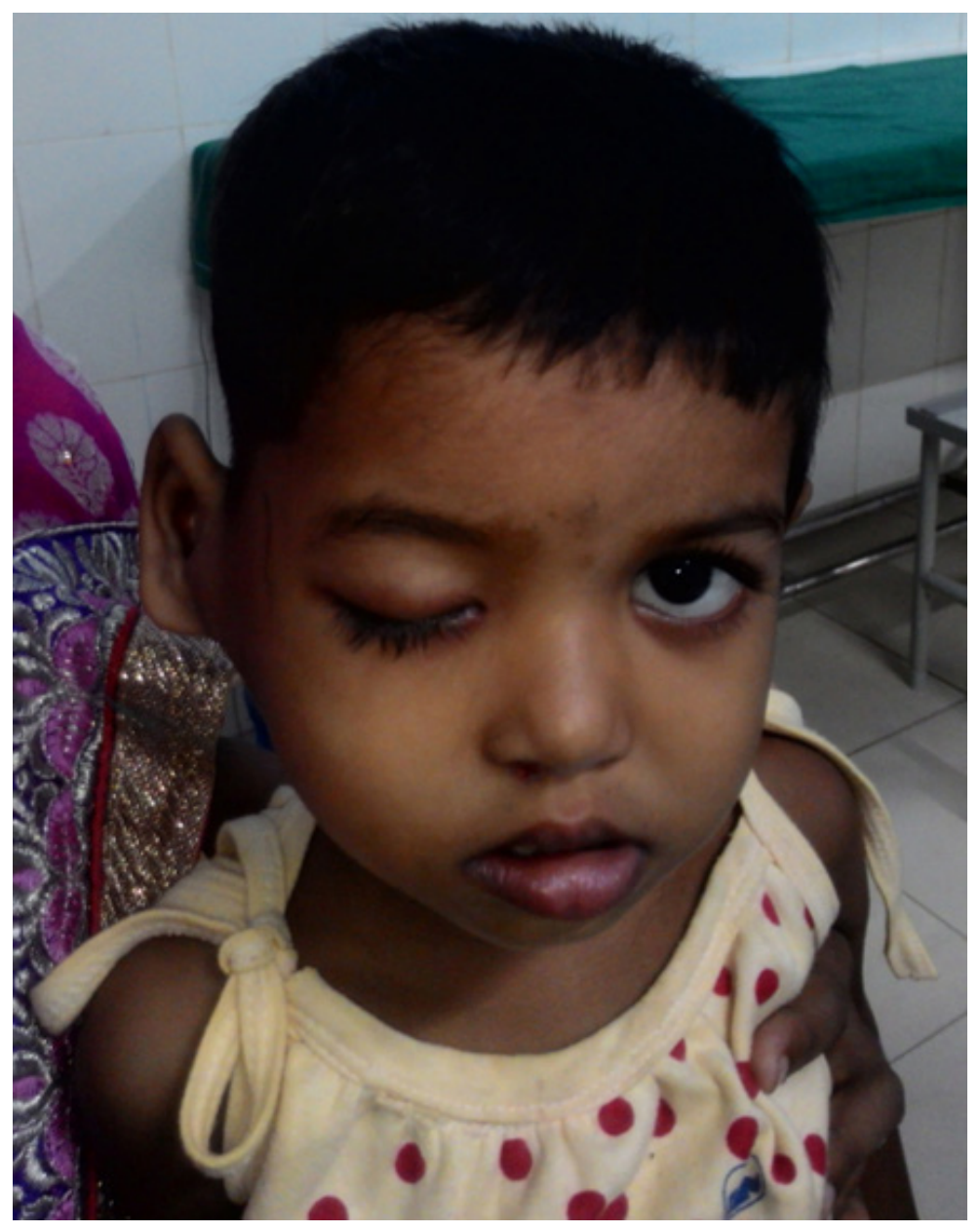

Figure 1: A 5year old girl presented with left side Bell's palsy. 